\title{
АНТЕННЫЙ ИЗЛУЧАТЕЛЬ ДЛЯ СИСТЕМ ДИАГНОСТИКИ ПОДПОВЕРХНОСТНЫХ ОБЪЕКТОВ
}

\author{
(C) В. Д. Сахацкий, А. Ю. Щеглов
}

Предложена конструкция ияилиндрической рупорной антеннь с двойньл изломом образующей и металлодиэлектрическим стержнем вдоль ее оси. Экспериментально подтверждено, что с помощью данного стержня при определенных его размерах возможно снижение ииринь диаграммы направленности антенны на $12^{\circ}$

Ключевые слова: ицлиндрическая рупорная антенна, металлодиэлектрический стержень, иирина диаграммы направленности, измерение

The construction of cylindrical horn antenna with double fracture of generator line and metallic dielectric core along its axe is proposed. It is experimentally proved that with this core of its certain size it is possible to reduction the width of antenna directivity pattern for $12^{\circ}$

Keywords: cylindrical horn antenna, metallic dielectric core, antenna beamwidth, measuring

\section{1. Введение}

Одним из эффективных методов исследования подповерхностной среды является георадарный метод. С его помощью можно фиксировать положение объекта контроля по характеристикам рассеяния электромагнитных волн на данном объекте. Одним из перспективных направлений применения георадаров является обследование автомобильных дорог [1-3]. Для этой цели используют георадары в мегагерцовом и гигагерцовом диапазонах частот. В частности, для контроля асфальтобетонных покрытий используют георадары в частотном диапазоне $1,5 \ldots 2$ ГГц. Разрабатываются и внедряются в производство радары, имеющие верхнюю частоту до 40 ГГц. Их глубина зондирования составляет единицы-десятки сантиметров и применяются главным образом для анализа состояния бетонных строительных конструкций [1].

\section{2. Постановка проблемы}

В качестве приемо-передающих антенн в системах контроля автодорожных покрытий обычно используют пирамидальные рупорные антенны. Для примера на рис. 1 показан антенный блок типа АВ-1700Р георадара «Око-2».

При определении границ подповерхностных объектов в измерительных системах целесообразно использовать приемо-передающие антенны с узкой диаграммой направленности (ДН). Для получения узких ДН используют антенны с круглым синфазным раскрывом, диаметр которого гораздо больше длины волны и амплитудное распределение поля в раскрыве близко К осесимметричному. К ним относятся параболические зеркальные антенны и цилиндрические рупорные антенны [4].

При взаимодействии с объектом контроля зондирующая волна с линейной поляризацией может изменить направление поляризации, что для пирамидальных рупорных антенн приведет к потере мощности отраженного сигнала на выходе приемной антенны. Поэтому целесообразно использовать такие антенны, которые бы были менее критичны к изменению поляризации отраженного излучения.
Такими антеннами также могут быть цилиндрические рупорные антенны.

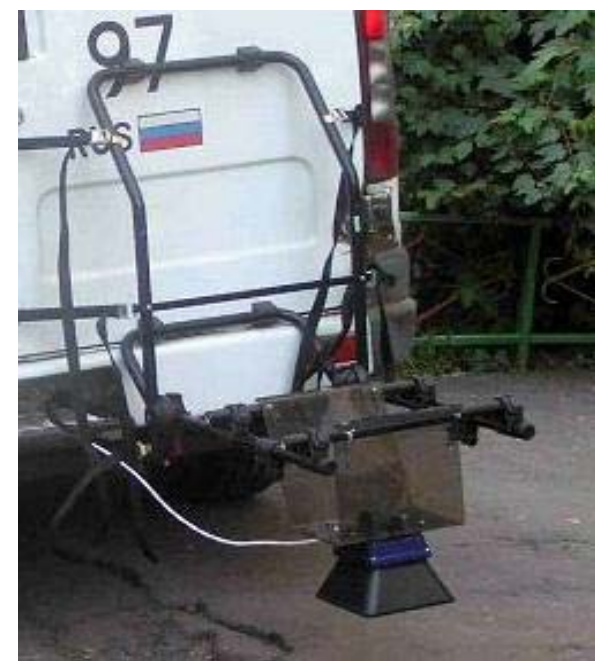

Рис. 1. Антенный блок георадара

\section{3. Литературный обзор}

Сужение диаграммы направленности рупорных антенн достигается различными способами. В частности, увеличением геометрических размеров антенны, созданием определенного амплитудно-фазового распределения на апертуре антенны либо при сохранении их размеров с помощью излома образующей [4, 5]. Получить узкую диаграмму направленности рупорной антенны можно также путем концентрации электромагнитного излучения вблизи направляющей структуры, расположенной на одной оси с волноводным излучателем. Примером таких антенн являются диэлектрические стержневые антенны [4], а также цилиндрическая рупорная антенна, описанная в работе [6]. Данная антенна представляет собой цилиндрический рупор, который запитывается от круглого волновода волной типа $\mathrm{E}_{01}$. В конической части рупорной антенны вдоль ее оси устанавливается специальный волновод, который выходит за пределы конической части антенны (апертуры) на определенное расстояние. Волновод составлен из электрически изолированных и установленных рядом друг с другом спиральных 
проводников. Такая конструкция антенны позволяет сконцентрировать излучение вдоль оси волновода и уменьшить ширину диаграммы направленности рупорного излучателя.

Целью статьи является экспериментальное исследование возможности сужения диаграммы направленности цилиндрической рупорной антенны с двойным изломом образующей.

\section{4. Антенный излучатель} на рис. 2.

Конструкция исследуемой антенны показана

Она представляет собой цилиндрическую рупорную антенну с двойным изломом образующей, по оси которой расположен цилиндрический стержень. Диаметр круглого волновода равен 21 мм. Длина образующей первой конической части рупора, прилегающей к волноводу, равнялась 48 мм, диаметр конуса в месте соединения со второй конической частью - 37 мм. Длина образующей второй части конуса - 40 мм и диаметр раскрыва антенны - 90 мм.

Стержень представлял собой фторопластовый цилиндр диаметром 10 мм, внутри которого вдоль его оси располагался медный провод диаметром 2 мм. Максимальная длина стержня составляла 110 мм. Осевое расположение стержня обеспечивала втулка из пенополистирола, которая помещалась в рупорную антенну и позволяла перемещать стержень вдоль оси антенны.

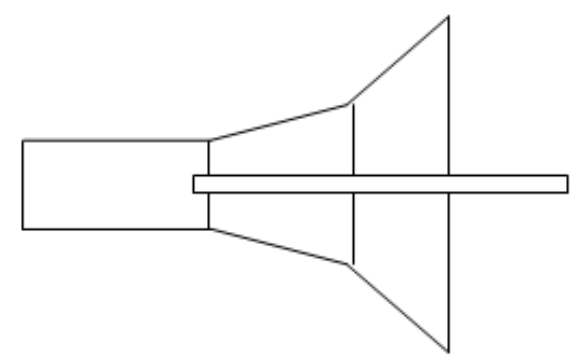

Рис. 2. Конический рупор с двойным изломом образующей и направляющим стержнем вдоль оси

Макет цилиндрической рупорной антенны с двойным изломом образующей показан на рис. 3. Здесь же показана пирамидальная рупорная антенна, которая использовалась при экспериментальных исследованиях в качестве передающей антенны. Так как передающая антенна возбуждалась волной типа $\mathrm{H}_{10}$, то в макет исследуемой цилиндрической антенны входил волноводный переход с круглого сечения на прямоугольный.

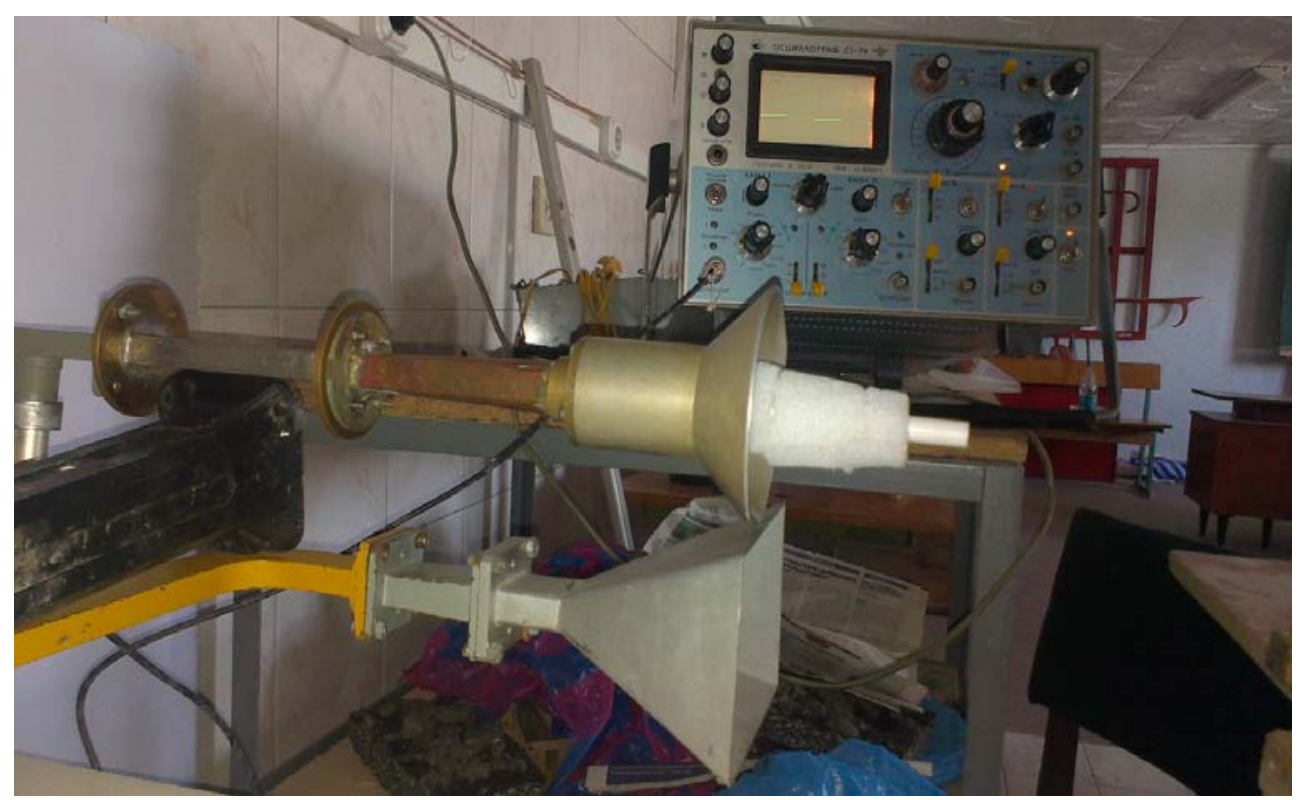

Рис. 3. Макет цилиндрической рупорной антенны с двойным изломом образующей и передающая антенна

Для исследования диаграммы направленности цилиндрической рупорной антенны была собрана измерительная установка, функциональная схема которой показана на рис. 4.

Элементы схемы имеют следующее назначение. Генератор типа ГЧ-32 А создает СВЧ излучение с длиной волны 3 см. Ферритовый вентиль компенсирует влияние нагрузки на работу генератора. С помощью аттенюатора типа Д5-5 изменяется мощность генератора. Гибкий волновод связывает волноводный тракт генератора с поднятой на высоту 1,5 м от поверхности пола передающей рупорной антенной.

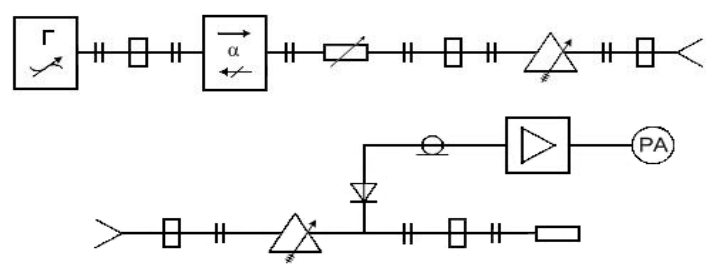

Рис. 4. Функциональная схема измерительной установки

C помощью согласующего трансформатора осуществляется согласование передающего тракта с антенной.

Приемная антенна устанавливается на поворотном устройстве и на той же высоте, что и 
передающая. Поворотное устройство имеет лимб, с помощью которого можно измерять угол поворота с точностью $\pm 0,5^{\circ}$. Детектор выделяет огибающую принятого СВЧ импульса, которая усиливается усилителем типа B6-4 и фиксируется его индикаторным устройством.

Методика измерений заключалась в следующем. Исследуемая рупорная антенна с двойным изломом образующей использовалась в качестве приемной антенны. Расстояние между приемной и передающей антеннами составляло 2 м и соответствовало условию излучения в дальней зоне. За начальный (нулевой) угол поворота приемной антенны принимался угол, соответствующий соосному расположению приемной и передающей антенн. В этом положении с помощью аттенюатора на индикаторном устройстве устанавливались определенные показания. Затем приемная антенна поворачивалась относительно оси передающей антенны влево или вправо на заданный угол и с помощью аттенюатора вновь добивались тех же самих показаний индикатора. Разница в показаниях аттенюатора означала выраженный в децибелах уровень ослабления мощности поступающей в приемную антенну под заданным углом. Таким образом, угловая зависимость уровня ослабления принимаемого сигнала соответствовала выраженной в децибелах диаграмме направленности исследуемой антенны.

Приведенные ниже результаты исследования соответствовали измерению диаграммы направленности в Н- плоскости.

Вначале измерялась диаграмма направленности приемной антенны без стержня на ее оси. Результаты измерений представлены на рис. 5. При каждом угле поворота антенны проводились многократные измерения и точки на рисунке соответствуют полученному среднему значению.

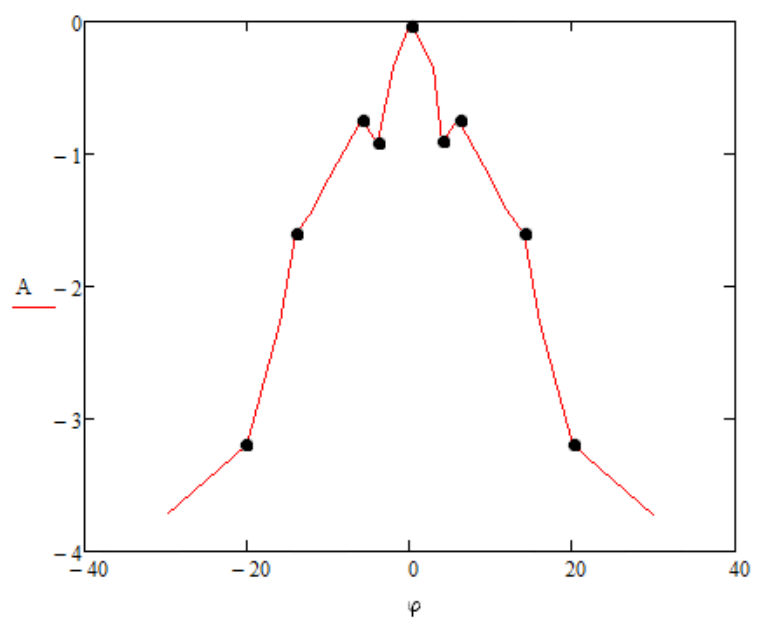

Рис. 5. Диаграмма направленности цилиндрической антенны с двойным изломом образующей

Из рисунка видно, что ширина диаграммы направленности по уровню -3 дБ равна $38^{\circ}$.

По аналогичной методике проведено экспериментальное исследование цилиндрической антенны при наличии металлодиэлектрического стержня. Изучалось влияние на ширину диаграммы направленности длины выступа металлодиэлектрического стержня за плоскость раскрыва антенны. Результаты измерений для длины выступа 90 мм, 65 мм и 48 мм показаны соответственно на рис. 6-8. Из рисунков видно, что установка вдоль оси антенны металодиэлектрического стержня приводит к уменьшению ее диаграммы направленности. Минимальная ширина диаграммы направленности $26^{\circ}$ имеет место при длине выступа стержня 90 мм. Выполнена оценка погрешности результатов измерений. Результаты расчета показали, что для доверительной вероятности $\mathrm{P}=0,95$ доверительный интервал не превышает $\pm 0,38$ дБ.

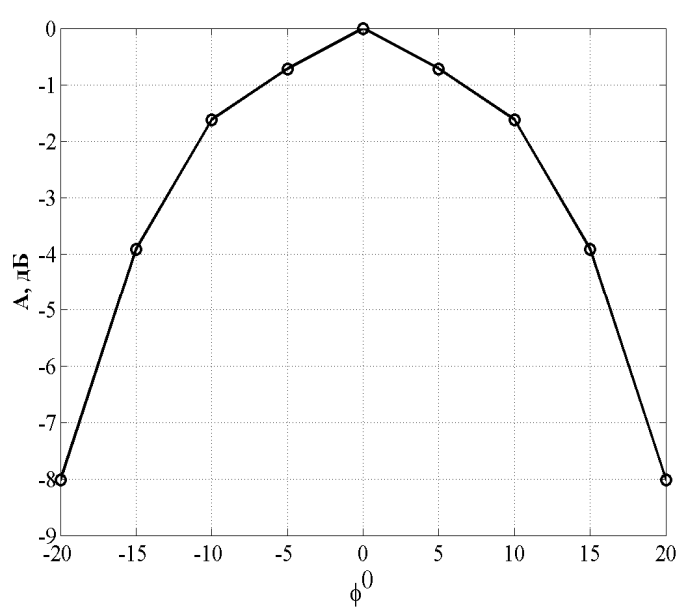

Рис. 6. Диаграмма направленности антенны с металлодиэлектрическим стержнем при длине его выступа 90 мм

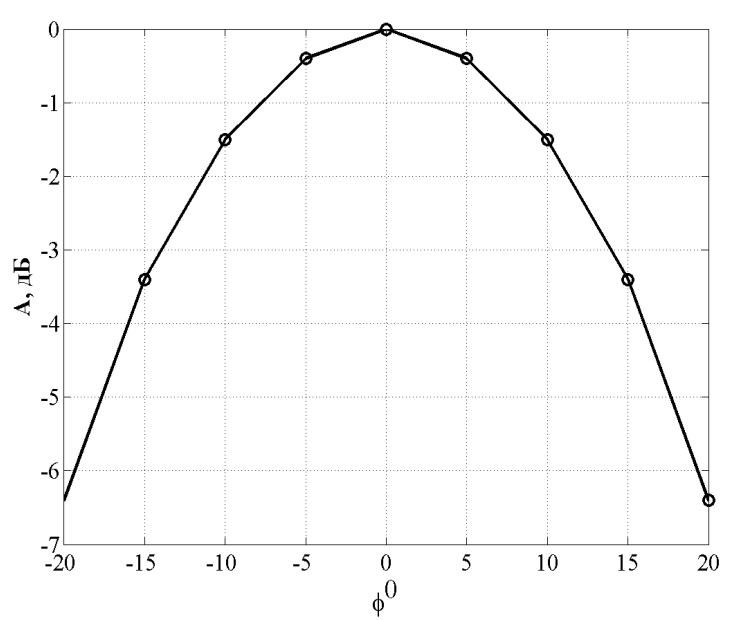

Рис. 7. Диаграмма направленности антенны с металлодиэлектрическим стержнем при длине его выступа 60 мм 


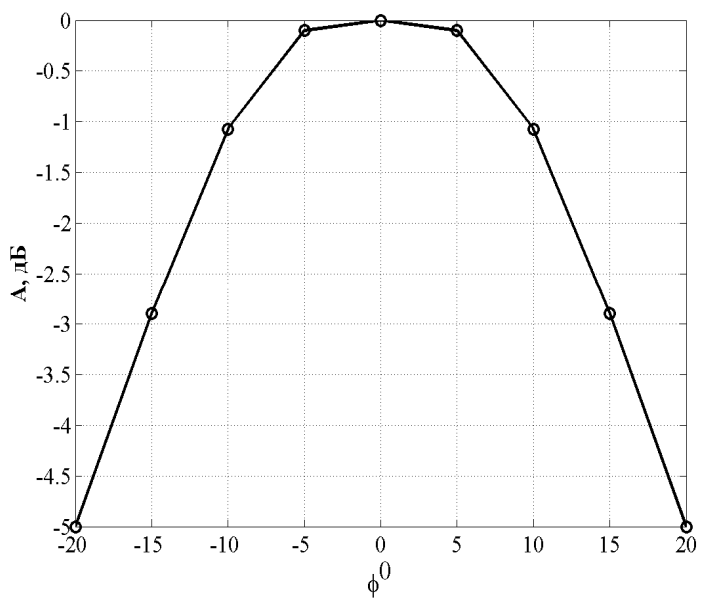

Рис. 8. Диаграмма направленности антенны с металлодиэлектрическим стержнем при длине его выступа 48 мм

Аналогичные исследования проведены при установки вдоль оси цилиндрической антенны металодиэлектрических стержней меньшей длины и других видов цилиндрических стержней. Последние были изготовлены из медной трубки, алюминиевого и стального проводов. Длина и внешний диаметр каждого стержня соответствовал размерам металлодиэлектрического стержня. Результаты исследования показали, что наиболее узкую диаграмму направленности антенны обеспечивает выше указанный металлодиэлектрический стержень.

\section{5. Выводы}

Проведенные экспериментальные исследования показали, что установка металодиэлектрического стержня вдоль оси цилиндрической антенны позволяет уменьшить ширину ее диаграммы направленности на $12^{\circ}$. Эффективность концентрации электромагнитного излучения вдоль оси антенны зависит от геометрических размеров и длины выступа стержня за пределы ее раскрыва.

Дальнейшие исследования данной антенны планируется провести для случая возбуждения ее волной типа $\mathrm{E}_{01}$.

\section{Литература}

1. Жилин, С. Н. Современные автоматизированные технические средства диагностики автомобильных дорог [Текст] / С. Н. Жилин, В. И. Ермолов. - Автомобильные дороги: Обзорн. информ ; вып. 2. - М.: Информавтодор, 2002. $-60 \mathrm{c}$.

2. Lin, J. Detection of Delaminating in Concrete Pavements Using Ground-Coupled Ground-Penetrating Radar Technique [Text] / J. Lin, D. G. Zollinger, R. L. Lytton // Journal of the Transportation Research Board. Transportation Research Board of the National Academies. - 2008. Vol. 2087, Issue 1. - P. 68-77. doi: 10.3141/2087-08

3. Cao, Y. Pavement Evaluation Using Ground Penetrating Radar [Text] / Y. Cao, B. B. Guzina, J. Labuz. University of Minnesota Final Report MN/RC 2008-10, 2008.

4. Антенны и устройства СВЧ [Текст] / под ред. Д. И. Воскресенского. - М.: Сов. радио, 1994. - 592 с.

5. Тимофеева, Н. А. Рупорная антенна с двойным изломом образующей [Текст] / Н. А. Тимофеева // Радиотехника. - 1975. - № 9. - С. 33-39.

6. Пат. 2328861 ФРГ, МКИ Н01Q 13-00. Verfahren und Anordnung zur Abstrahlung scharf gebundelter elektromagnetischer Wellen [Текст] / T. Johann. - заявитель и патентообладатель Siemens AG Berlin und Munchen. № Р 2328861.1; зявл. 6.6.73; опубл. 20.2.75.

\section{References}

1. Gilin, S. N., Yermolov, V. I. (2002). Modern automotized technical equipment for diagnostic motor ways. Motor ways: survey information; number 2. Moscow : Informavtodor, 60.

2. Lin, J., Zollinger, D. G., Lytton, R. L. (2008). Detection of Delaminating in Concrete Pavements Using Ground-Coupled Ground-Penetrating Radar Technique, Journal of the Transportation Research Board. Transportation Research Board of the National Academies, 2087 (1), 68-77. doi: 10.3141/2087-08

3. Cao, Y., Guzina, B. B., Labuz, J. (2008). Pavement Evaluation Using Ground Penetrating Radar, University of Minnesota Final Report MN/RC 2008-10.

4. Voskresensky, I. (Ed.) (1994). Antennas and SHF appliances. Moscow: Soviet radio, 592.

5. Timopheieva, N. A. (1975). Horn antenna with double rupture of generator line. Radiotechnics, 9, 33-39.

6. Johann, T. (1975). Patent 2328861 FRG, IPC H01Q 13-00. Method and system for sharply focused radiation of electromagnetic waves./; patent applicant and patent owner Siemens AG Berlin und Munchen. № P 2328861.1; decl. 6.6.73; published 20.2.75.

Сахацкий Виталий Дмитриевич, доктор технических наук, профессор, кафедра метрологии и безопасности жизнедеятельности, Харьковский национальный автомобильно-дорожный университет, ул. Петровского, 25, г. Харьков, Украина, 61002

E-mail:svd@rks.kh.ua

Щеглов Александр Юрьевич, кафедра метрологии и безопасности жизнедеятельности, Харьковский национальный автомобильно-дорожный университет, ул. Петровского, 25, г. Харьков, Украина, 61002 